\title{
A REPRESENTAÇÃO FEMININA NAS UNIVERSIDADES E A CONCREÇÃO DA CIDADANIA
}

\author{
WOMEN'S REPRESENTATION IN UNIVERSITIES AND THE \\ CONCRETION OF CITIZENSHIP
}

\author{
Danilo Henrique Nunes ${ }^{\mathrm{I}}$ \\ Selma Tomé Pina ${ }^{\mathrm{II}}$ \\ Juvêncio Borges Silva ${ }^{\text {III }}$
}

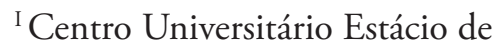
Ribeirão Preto, Ribeirão Preto, SP; Centro Universitário da Fundação Educacional de Barretos, Barretos, SP e Universidade de Ribeirão Preto, Ribeirão

Preto, SP, Brasil. Doutorando em

Direitos Coletivos e Cidadania. E-mail: dhnunes@hotmail.com

II Universidade de Ribeirão Preto,

Ribeirão Preto, SP, Brasil. Doutoranda em

Direitos Coletivos e Cidadania. E-mail: selmactome@gmail.com

III Universidade de Ribeirāo Preto, Ribeirão Preto, SP, Brasil. Doutor em Direito. E-mail: jsilva@unaerp.br

DOI: http://dx.doi.org/10.31512/rdj.v21i41.634

Recebido em: 11.02.2020

Aceito em: 14.05.2021

\begin{abstract}
Resumo: Este trabalho faz uma abordagem qualitativa e quantitativa da presença das mulheres no ensino superior brasileiro, trazendo dados oficiais do Censo da Educação Superior do Instituto Nacional de Estudos e Pesquisas Educacionais Anísio Teixeira (Inep/MEC) e dados da Universidade do Estado de Minas Gerais - Unidade Passos, (UEMG-PASSOS). O objetivo do estudo é discutir a representatividade da mulher na universidade e sua importância para a concreção da cidadania feminina. Os números comprovam que as mulheres são maioria nos cursos superiores, no entanto, elas ocupam majoritariamente as vagas nos cursos de licenciatura e humanas, enquanto os homens são maioria nos campos de engenharias e tecnológicas, o que, em tese, perpetua a tradicional divisão sexual do trabalho e mantém a mulher longe de equidade de gênero no ambiente acadêmico. $\mathrm{O}$ estudo foi elaborado através de análise de dados consolidados, relatórios oficiais do governo, relatório da UEMG-Passos, além da mobilizaçáo da literatura especializada.
\end{abstract}

Palavras-chave: Mulheres; Gênero; Educação.

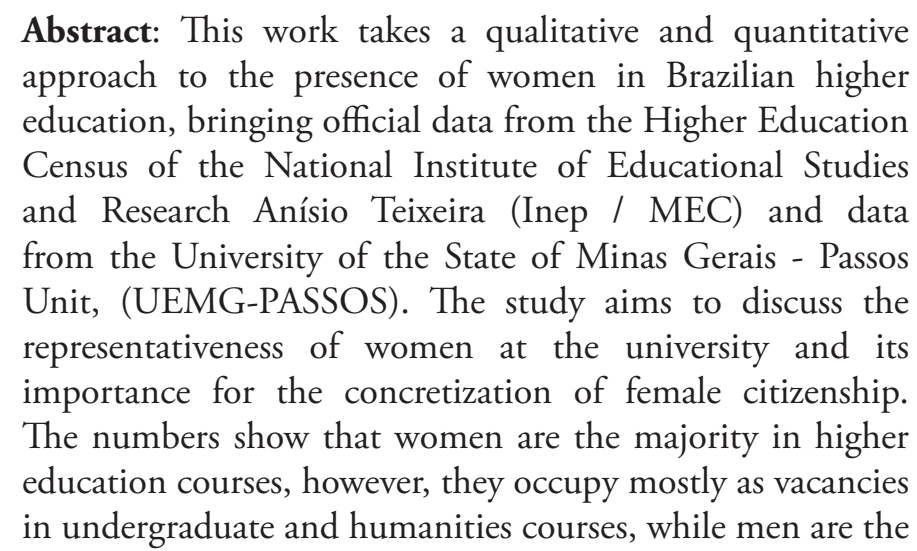


majority in the fields of engineering and technology, which, in theory, perpetuates the sexual division of traditional work environment and keeps women away from gender equality in the academic environment. The study was carried out through the analysis of consolidated data, official government reports, UEMG-Passos report, in addition to the mobilization of specialized literature.

Keywords: Women; Gender; Education.

\section{Introduçáo}

No Brasil a educação é direito fundamental consagrado pela Constituição da República e, mundialmente, pela Declaração Universal dos Direitos Humanos. É um direito de todos, homens, mulheres e crianças sem distinção de raça, cor, crença ou etnias.

A Lei de Diretrizes e Bases (Lei no 9.394, de 20 de dezembro de 1996) que estabelece as diretrizes e bases da educação nacional no Brasil, também declara ser a educação direito fundamental e, mais ainda, a mola propulsora para se construir um mundo mais seguro e sadio, ambientalmente equilibrado, que favoreça o progresso social, econômico e cultural.

Apesar da norma ser taxativa sobre ter direito à educação, sabemos que esta não é suficiente para promover a equidade e consolidar cidadania. A educação brasileira, em termos gerais, apresenta graves deficiências, exclui muitas crianças, jovens e adultos e, faz-se necessário constante incremento de políticas públicas para que ela possa ser oferecida.

Este trabalho vai abordar especificamente a presença das mulheres no ensino superior brasileiro, estudando os dados do Censo da Educação Superior e, com um recorte especial analisando os números da Universidade do Estado de Minas Gerais - Unidade Passos, (UEMGPASSOS) com o objetivo de discutir representatividade na universidade e a importância desta para a concreção da cidadania feminina.

Iniciamos contextualizando legalmente o direito a educação e logo em seguida apresentamos dados estatísticos brasileiros. Fazemos também uma contextualização do ensino superior, suas modalidades e especificidades e, já na discussão do problema de estudo apresentamos como a mulher está inserida no universo do ensino superior, demonstrando através dos dados onde e como ela se apresenta como estudante do ensino superior e, se esta presença em determinados cursos tem ligação direta com a questão de gênero.

Os números comprovam que as mulheres são maioria nos cursos superiores, no entanto, elas ocupam majoritariamente as vagas nos cursos de licenciatura e humanas, enquanto os homens são maioria nos campos de engenharias e tecnológicas, o que, em tese, perpetua a tradicional divisão sexual do trabalho e mantém a mulher longe de equidade de gênero no ambiente acadêmico.

O estudo foi elaborado a partir de análise de dados consolidados, relatórios oficiais do governo, relatório da UEMG-Passos, além da mobilização da literatura especializada. 


\section{Educaçáo como direito fundamental, gênero e cidadania feminina}

Direito Fundamental consagrado na Constituição Federativa do Brasil promulgada em 1988, a educação está prevista no rol dos direitos sociais presentes no Art. $5^{\circ}$ e mais especificamente no art. 205 que diz: "A educação, direito de todos e dever do Estado e da família, será promovida e incentivada com a colaboraçáo da sociedade, visando ao pleno desenvolvimento da pessoa, seu preparo para o exercício da cidadania e sua qualificação para o trabalho".

A Declaração Universal dos Direitos Humanos também tem destaque para a educaçáo. Vejamos:

Art. 22. Todo ser humano, como membro da sociedade, tem direito à segurança social, à realização pelo esforço nacional, pela cooperação internacional e de acordo com a organização e recursos de cada Estado, dos direitos econômicos, sociais e culturais indispensáveis à sua dignidade e ao livre desenvolvimento da sua personalidade. A educação é a mola mestra de desenvolvimento do mundo (BRASIL, 2007).

É pela educação que as normas de conduta da sociedade são incutidas nas novas geraçôes.

Para Adorno (1995), educação é primordial para a formação ética dos seres humanos e para a construção da cidadania, pois lida com as dimensôes social e cultural dos indivíduos, ela ainda, se ancora nos princípios éticos, ou seja, nos valores definidos e praticados na sociedade em que está inserida.

Tais princípios precisam ser aprendidos e, portanto, devem ser ensinados, daí o papel da Instituição Escolar. A escola é a instituição responsável por promover a inserção das pessoas na comunidade, e por meio de um diálogo contínuo com a sociedade, é também, capaz de propor ações de enfretamento à todas as formas de exclusão social.

De acordo com Lodi e Araújo, dois fatores são necessários para a introjeção de princípios éticos e educacionais:

1) Que os princípios se expressem em situaçóes reais, nas quais possam ter experiências e nas quais possam conviver com a sua prática;

2) que haja um desenvolvimento da sua capacidade de autonomia moral, isto é, da capacidade de analisar e eleger valores para si, consciente e livremente (in MINISTÉRIO DA EDUCAÇÃO, 2007, P. 69).

De acordo com Freire (2005), mais do que discursos, a educação solicita de reflexóes sobre a prática e vivências em situações reais. Por meio das experiências o sujeito compreende a necessidade do diálogo, do respeito para si e com o próximo, e do que é ser solidário e justo. Estas discussóes educacionais são essenciais para a construção da cidadania e, devem voltar-se para a compreensão da realidade social, dos direitos e deveres do cidadáo, e pautar-se nos princípios éticos e morais da nossa sociedade.

Ainda segundo Freire (2005), a educação deve ser vista como prática de liberdade, interligando e envolvendo os homens em uma realidade concreta que traga mudanças que se 
propóem necessárias, sobre as verdadeiras realidades e contextos dos seres humanos em suas vivências e, que a partir da educação possa se consolidar a consciência e a transformação dos seres humanos.

Nesta linha, os ensinamentos de Moram (2007) demonstram que enquanto instituição pública, a escola é um espaço social e político que tem por finalidade educar as futuras geraçôes, transmitindo assim os conhecimentos acumulados pela nossa civilizaçáo, mas deve se ocupar também com a construção do indivíduo em sua totalidade, preparando-o para a vida em sociedade.

Neste contexto podemos dizer que a inserção da mulher na educação é fator imprescindível para a promoção, por exemplo, da representatividade feminina nas diversas esferas do poder, pois apesar de representar mais de 50\% do eleitorado brasileiro, a mulher não alcança porcentagem mínima nos cargos políticos no Brasil. Isso porque, a desigualdade de gênero acarreta a predominância masculina nas relaçóes de poder, confirmando o círculo vicioso que mantém a mulher submissa à sociedade e a dominância masculina.

Para Pereira e Lehfeld (2018) a titularidade de direitos da mulher foi reconhecida tardiamente e, isto seria causa impactante no cotidiano feminino refletindo diretamente na condição da mulher como sujeito capaz de ocupar espaços sociais, culturais, políticos e econômicos a partir de suas próprias identidades e necessidades, perpetuando as desigualdades entre homens e mulheres.

Os autores destacam que, "é notório o progresso das mulheres na sociedade e a existência do aparato legislativo. Entretanto, a mulher está no percurso da construção da cidadania, dentro de uma sociedade patriarcal, sem os mesmos privilégios conferidos os homens" (p.485) e, sem construção de políticas públicas reconhecendo a mulher como sujeito de direitos, ela continuará a ser vítima de discriminação, com seus direitos fundamentais violados e, sem assegurar e exercer sua cidadania, apesar desta ser positivada como direito fundamental. "A mulher não está presente nas relaçóes de poder. Não exerce os direitos fundamentais à vida, à saúde, à educaçáo, ao trabalho, à dignidade, à igualdade, a viver uma vida livre de violência, etc. A reflexão deságua, portanto, na seguinte questão: a legislação é suficiente?” (p.487)

Em breve conclusão temos que a cidadania às mulheres, apesar de garantida, não é efetivada de forma plena e, portanto, náo pode ser exercida. $\mathrm{O}$ reconhecimento da mulher como sujeito de direitos ocorreu, mas questiona-se no plano da realidade que esta cidadania é exercida em seu conceito restrito, qual seja a concreção do "direito a ter direitos"1.

O lugar "doméstico", determinado para a mulher ao longo da história, reverbera através dos séculos com discursos que produziram e naturalizaram a desigualdade entre homens e mulheres e, promovem um apagamento de seu papel como protagonista na formaçáo do mundo.

1 Hannah Arendt afirma que o direito a ter direitos significa viver numa estrutura onde se é julgado pelas ações e opinióes e de um direito de pertencer a algum tipo de comunidade organizada (ARENDT, 1990, p. 330). 
De acordo com Melo e Thomé (2018), as desigualdades de gênero também estão presentes quando se trata da história da educação e as mulheres são excluídas. E como a história foi escrita pelos homens, as mulheres sempre foram menosprezadas, sem direito a voz e tituladas como causadoras dos infortúnios humanos.

Seria preciso voltar muitos séculos, milênios, e deles trazer Hipátia, Cleópatra, Joana D'Arc, entre tantas outras, para fazer jus ao papel das mulheres na história das civilizaçôes. Uma participação da qual muito pouco se sabe, tanto porque as mulheres estavam confinadas principalmente em seus lares, como também devido aos poucos registros de suas ações (MELO; THOMÉ, 2018, p. 37).

Hipátia de Alexandria, por exemplo, foi uma cientista pagã, matemática, filósofa, médica e astrônoma do século IV a V d.C., Cleópatra foi rainha do Egito, um dos grandes impérios da antiguidade, no século I a.C., e Joana D’Arc foi uma líder guerreira do período medieval. Além dessas mulheres, existiram muitas outras, cujos feitos permaneceram no esquecimento, pois a história se encarregou de apagá-las. Acerca desse fenômeno, Perrot (2007) declara que nunca teremos uma ideia real de seus feitos, pois, as poucas histórias narradas são frutificadas a partir do imaginário dos homens.

Neste contexto, pode se entender que a educação para a mulher nunca foi pensada como forma de promover e consolidar cidadania e consequente, participação pública.

\section{Os Números no Ensino Superior}

Nos últimos anos, mais especificamente a partir da década de 90, o estado implantou uma série de políticas universais de inclusão social, entre elas o acesso à educação superior como forma de criar oportunidades e desenvolvimento econômico e social. Estas políticas de inclusão, promoveram uma lenta mudança no cenário universitário com a ampliação da ocupação pelas mulheres de vagas em curso de graduação, por exemplo.

Houve ainda, um aumento significativo no número de instituições de ensino superior no Brasil a partir do governo Lula, com a implantação de universidades públicas e institutos federais, divididos por regiōes, saindo dos grandes centros e indo para os interiores e regiôes.

Foram criadas 18 novas universidades federais e 173 campus universitários, praticamente duplicando o número de alunos entre 2003 a 2014: de 505 mil para 932 mil. Os institutos federais também tiveram uma grande expansão durante os governos do PT: foram implantados mais de 360 unidades por todo o país. (PARTIDO DOS TRABALHADORES, 2018, n.p.)

De acordo com pesquisa do Instituto Nacional de Estudos e Pesquisas Educacionais Anísio Teixeira (Inep/MEC) realizada em 2017, o Brasil à época contava com 2448 instituiçôes de ensino superior. Destas 296 públicas e 2.152 privadas. Os dados demonstram ainda que dentre as públicas, $41,9 \%$ são estaduais; $36,8 \%$, federais e 21,3\%, municipais. 
A pesquisa ainda delimita que aproximadamente $3 / 5$ das instituiçóes federais são universidades e outros 36,7\%, Institutos Federais de Educação, Ciência e Tecnologia (IFs) e Centros Federais de Educação Tecnológica (Cefets). Desmembrando estes números as faculdades totalizam $82,5 \%$ e as universidades equivalem a $8,1 \%$ do total de IES.

A maioria dos estudantes, $53,6 \%$, estão matriculados nas universidades e apenas $1 / 4$ estão nas faculdades. Com relação aos cursos, na graduação se dividem em bacharelado e licenciatura, ensino presencial e na modalidade a distância (EAD), sendo, predominante, matrículas nos cursos de bacharelado (58,7\%).

Ainda de acordo com o Inep/MEC (2017, on-line) "o Censo da Educação é o mais completo levantamento estatístico sobre as IES brasileiras e sua oferta de cursos", é realizado com o objetivo de oferecer para o poder público diretrizes de aprofundamento e criação de políticas públicas no setor educacional, bem como de dar à sociedade parâmetros sobre a situação da política de educação brasileira.

Os dados do Inep/MEC, são orientados através do Censo Escolar, regulamentado pelo Decreto no 6.425 de 04/04/2008, é realizado anualmente com o objetivo de organizar informaçóes sobre as IES brasileiras, com dados sobre os cursos de graduação, estudantes, docentes e técnicos/ as vinculados a esse nível de ensino, número de ingressantes e de concluintes, por sexo, idade, região do País, número de vagas em cursos de graduação, por modalidade de ensino e tipo de vaga, caracterizando o mais completo instrumento de avaliação do ensino superior.

De acordo com o INEP, em dados de 2018, 17\% da população brasileira de 25 a 64 anos de idade havia concluído um curso de ensino superior no nível de graduação, 0,8\% concluíram mestrado e $0,2 \%$ doutorado.

\subsection{Os números na sala de aula}

Houve uma crescente expansão da escolaridade no Brasil a partir da década de 1970, com grande destaque para a contingência feminina que tenta reverter a desigualdade histórica. A predominância das mulheres no ensino superior está impressa nos dados do Censo. Elas são maioria de ingressantes, matriculados e concluintes sendo, 55\% ingressantes, 57\% matriculadas e $61 \%$ concluintes dos cursos de graduação.

Outro dado de destaque na pesquisa é o que demonstra uma maior presença de mulheres matriculadas nas licenciaturas, sejam elas nos cursos presenciais ou na modalidade EAD, sendo $70,6 \%$. Este percentual só diminui quando a idade é superior aos 60 anos, que compreende formação pela Educação Jovens e Adultos (EJA).

A figura 1, a seguir, ilustra esses dados, no Brasil, em 2018: em verde claro temos o quantitativo de mulheres e em verde escuro o de homens matriculados na educação profissional, ainda podemos comparar tais dados de acordo com a faixa etária dos mesmos. Observe que as 
mulheres compreendem a maioria das matrículas em todas as faixas etárias, excluindo-se apenas a faixa de 60 anos ou mais.

Gráfico 1 - Número de matrículas na educação profissional segundo faixa etária e sexo - Brasil - 2018

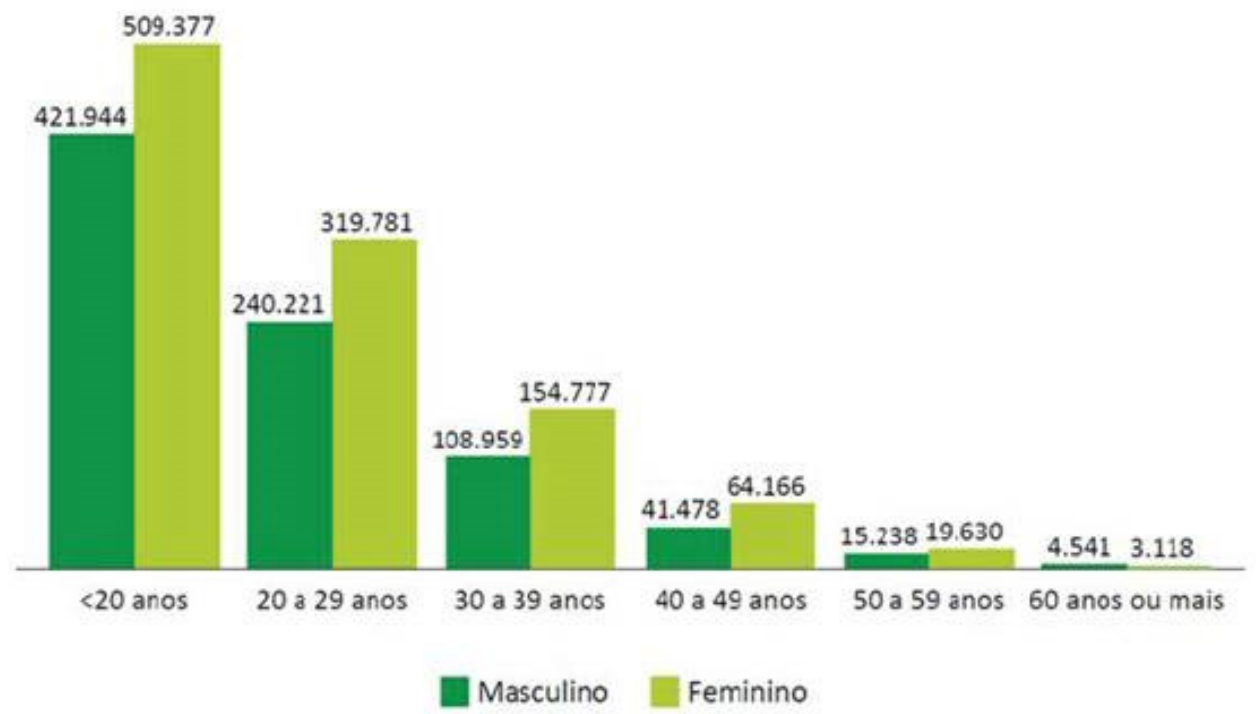

Fonte: Elaborado pela Deed/Inep com base nos dados do Censo da Educação Básica

Elas também são maioria esmagadora nos cursos profissionais da Educação Básica com predominância em todas as faixas etárias ${ }^{2}$. No entanto, é possível afirmar que

$\mathrm{O}$ intenso avanço do ponto de vista quantitativo, contudo, mascara alguns aspectos de exclusão e segmentação do processo de entrada das mulheres nas universidades. Igualdade numérica não significa equidade de gênero, uma vez que a tendência de maior peso feminino nas carreiras de menor prestígio e mais mal remuneradas se acentua ao longo do período (GUEDES, 2008, p. 125).

Assim, considerando os dados do Censo, é certo concluir que no Brasil a presença feminina no ensino superior cresceu progressivamente nos últimos anos, porém ainda é clara a diferença na escolha da mulher por cursos em áreas reconhecidamente femininas pela sociedade, como nos cursos das áreas de formação educacional básica, ou seja, nas licenciaturas, onde a presença das mulheres chega próximo aos $60 \%$ de concluintes, contra $41 \%$ quando são considerados os cursos relacionados às ciências exatas e da saúde, como os de biologia, farmácia, engenharias, matemática, medicina, física, química, ciência da computação, entre outros. Finalmente, tais dados nos impelem a corroborar com Dubet (2001, p. 11), ao afirmar que "as mulheres dominam os serviços, são majoritárias na educação e na saúde, mas não entram na produção, na política ou em outros setores que continuam predominantemente masculinos", uma vez que se qualificam, majoritariamente, para as áreas humanas do conhecimento. Outrossim, essa aparente igualdade educacional se reverbera em

2 De acordo com o Censo Escolar a educação profissional engloba cursos de formação inicial e continuada, qualificação profissional articulado à EJA ou ao ensino médio; ou ainda os cursos técnicos de nível médio nas formas articuladas (integrada ou concomitante) ou subsequente ao ensino médio. 
diversas outras desigualdades, sejam salariais, setoriais e para a formação inicial ou continuada dos sujeitos femininos.

\subsection{Os números na UEMG-Passos}

Seguindo os mesmos parâmetros do Censo da Educação Superior, realizamos uma pesquisa junto à Secretária Acadêmica da Universidade do Estado de Minas Gerais - Unidade Passos. (UEMG-PASSOS). Para este estudo, foram considerados dados de ingressantes e concluintes nos 21 cursos de graduação da universidade de acordo com o sexo, nos anos de 2017,2018 e 2019.

Os dados confirmam a tendência nacional com maior número de mulheres matriculadas e concluintes e, ainda, maior número nas licenciaturas e nos cursos das áreas de humanas, ficando os homens, majoritariamente, concentrados nas áreas de ciências exatas e tecnológicas, como nas engenharias e sistemas de informação.

Em 2017, foram efetuadas 2.608 matrículas de mulheres contra 2.099 de homens. Em 2018, houve um pequeno aumento no número de mulheres e de homens, sendo 2.645 vagas ocupadas pelo público feminino e 2.120 para o masculino. Já em 2019, as mulheres continuaram maioria efetivando 2.622 matrículas e os homens 2.063 .

Nos gráficos a seguir, veremos os números de alunos matriculados por curso e gênero nos anos de 2017, 2018 e 2019, sucessivamente, na Universidade do Estado de Minas Gerais Unidade Passos (UEMG-PASSOS).

Gráfico 2 - Alunos matriculados por curso referente ao ano de 2017

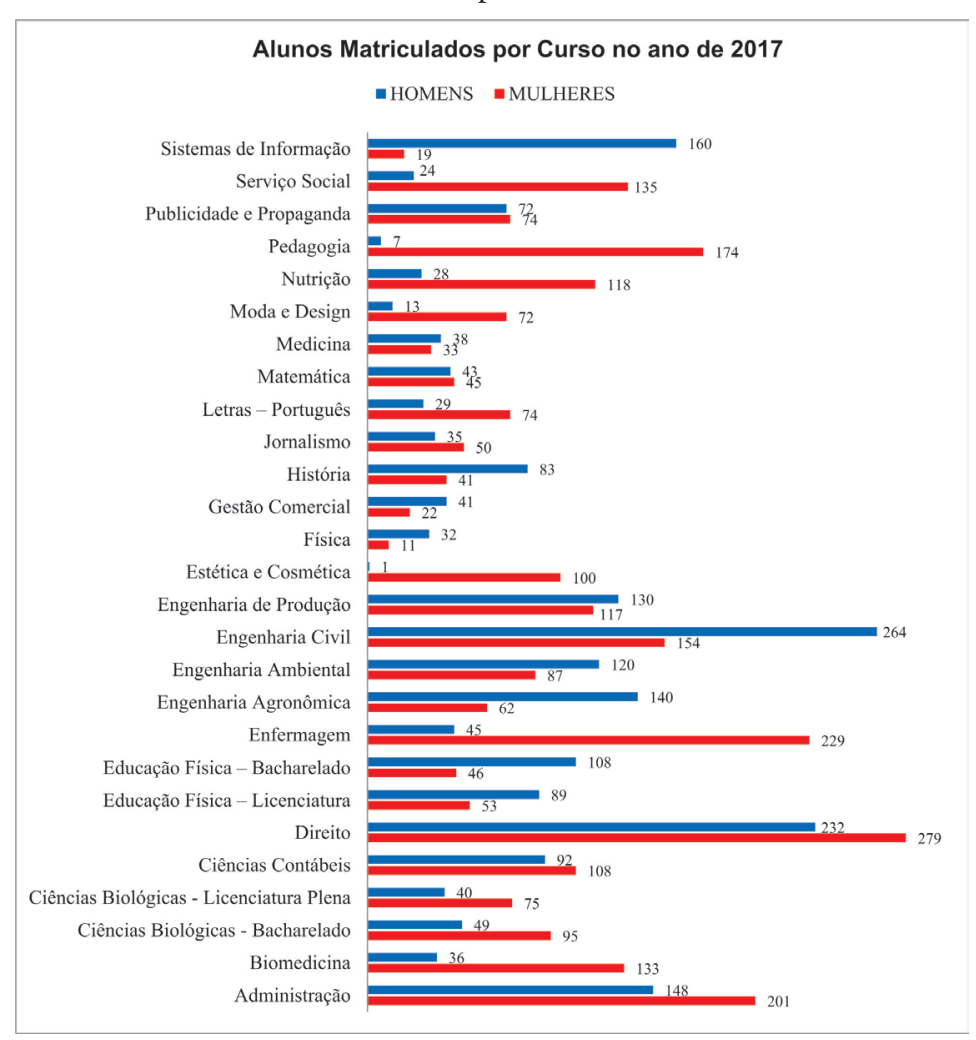

Fonte: Elaborado pelos autores 
Gráfico 3 - Alunos matriculados por curso referente ao ano de 2018

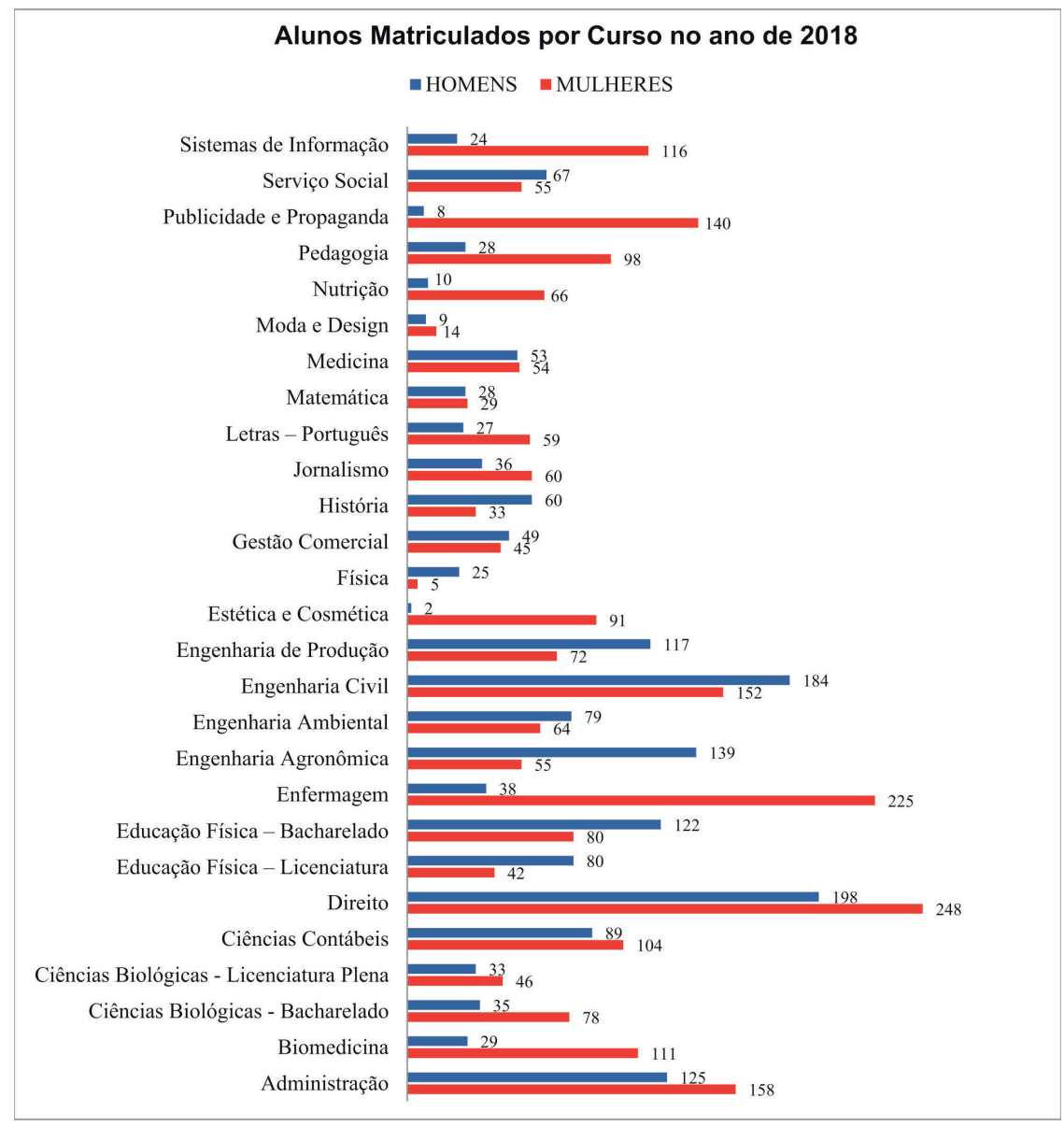

Fonte: Elaborado pelos autores

Gráfico 3. Alunos matriculados por curso referente ao ano de 2019

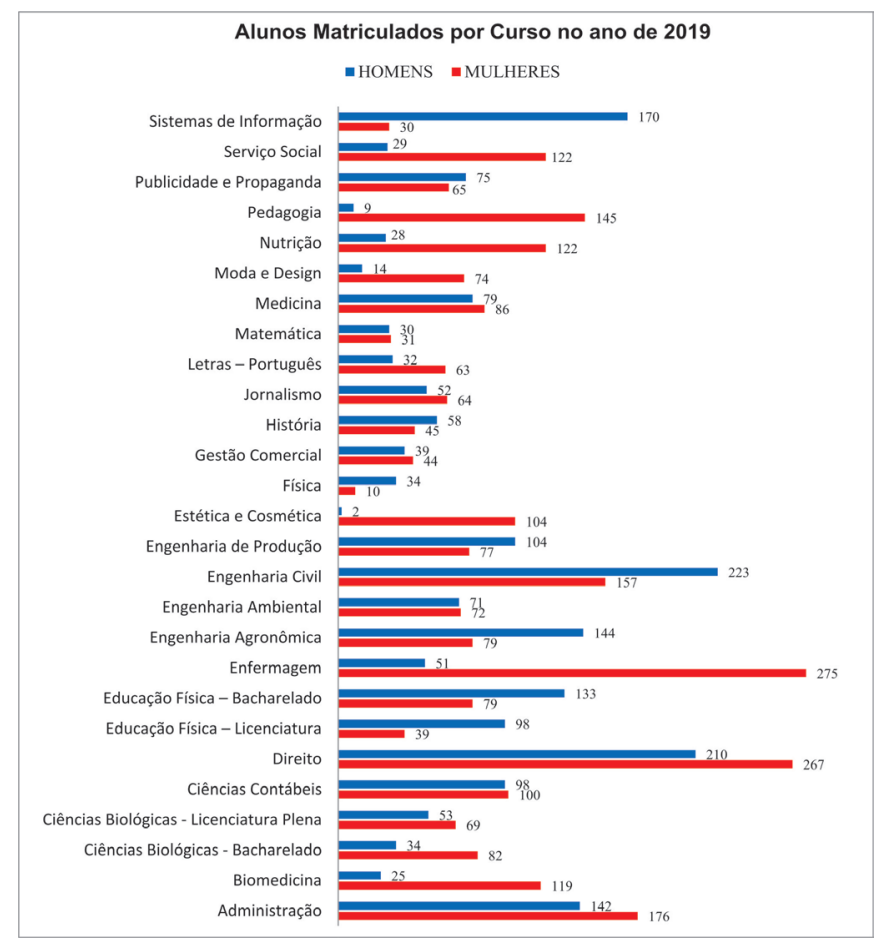

Fonte: Elaborado pelos autores 
Cabe aqui mencionar que o aumento nos índices de escolaridade, nas últimas décadas, foi percebido em todos os níveis de educação. No ensino superior, conforme dados apresentados nos gráficos 1, 2 e 3, vemos, em números gerais, majoritariamente as mulheres em busca de qualificação profissional, o que não repercutiu exatamente na inserção igualitária da mulher no universo laboral, uma vez que, algumas áreas de conhecimento ainda continuam marcadamente segmentadas, tais como: TI e engenharias.

[...] do ponto de vista das relaçóes de gênero, as preferências quanto à escolha dos cursos foram se construindo ao longo do processo de escolarização dos sujeitos femininos e masculinos, dando origem a áreas demarcadas como mais "femininas", como a área das ciências humanas e a maior parte dos cursos da saúde, ou mais "masculinas", como aqueles da área das ciências exatas e carreiras tecnológicas (ÁVILA; PORTES, 2009, p. $95)$.

Assim, ainda hoje, a diferença nos cursos mostram-se maiores quando consideradas as áreas de formação educacional como nos curso de Pedagogia e Letras e, de formação e atuação social, humana, de estética e moda, como nos cursos de Serviço Social, Enfermagem, Biomedicina, Nutrição, Estética e Cosmética e moda e Design. Já nos cursos de formação tecnológica e exatas predominam os homens como nas Engenharias: Civil, Ambiental, Produção e Agronômica, e no curso de Sistemas de Informação onde temos a maior diferença.

Observe que com a perda de prestígio das licenciaturas nas últimas décadas, a participação feminina em outros vestibulares acabou se ampliando, contudo, ainda é perceptível as marcações que destinam áreas específicas para cada gênero.

Podemos, neste momento, evocar a questão da vocação para determinadas carreiras, entretanto, também podemos inferir a "força do poder do poder simbólico (travestido de falsa consciência)" (ÁVILA; PORTES, 2009, p. 99), aquela que tem o poder de maquiar, mas que reforça ainda mais a dominação masculina, seja no campo do trabalho ou no momento da escolha de um curso superior. Todavia, as mulheres mais jovens e detentoras de maior capital cultural têm mais condiçôes de se emanciparem dessa dominação.

Cabe aqui mencionar que os bens culturais são transmitidos entre as geraçôes, mas nem todos possuem os meios para deles se apropriarem, ou seja, nem todos "detêm o código que permite decifrá-los" Bourdieu (2003, p. 297), uma vez que para se apropriar de tal código, desde o início da trajetória escolar é necessário o amplo acesso aos recursos pedagógicos, aos livros e bibliotecas, às tecnologias educacionais, à alimentação e moradia adequadas, entre outros.

\section{A importância do ensino superior nas relaçóes de gênero para a concreçáo da cidadania}

Conforme demonstrado pela pesquisa é inegável que as mulheres estão ocupando os bancos das universidades, faculdades e institutos de educação. Inegável ainda, que esta formação superior é um grande avanço na luta feminista em busca de equidade e efetivação de direitos 
para que se alcance plena cidadania. No entanto, estes mesmos números comprovam que esta ocupação, apesar de ser majoritária em relação ao universo masculino, não se reflete na mesma medida em reconhecimento do papel da mulher na sociedade como importante meio para a promoção social e crescimento econômico, por exemplo.

O relatório Education at Glance 2019, produzido pela Organização para a Cooperação e Desenvolvimento Econômico (OCDE) e divulgado pelo Brasil através do INEP (2019), aponta os inúmeros preconceitos e discriminaçôes existentes na educação com relação as questôes envolvendo a mulher e, perpetuando estereótipos de gênero. Um exemplo seria o fato de as mulheres serem desestimuladas a seguir carreira nas ciências exatas por teoricamente terem uma falta de aptidão natural nestas áreas onde há um ambiente ainda muito hostil encontrado nas academias e em espaços empresariais.

O relatório exemplifica ainda que a taxa de emprego brasileira é influenciada pelo nível de escolaridade, com o ensino superior ocupando $83 \%$ das vagas.

No Brasil, a escolaridade tem maior impacto para as mulheres do que para os homens no acesso ao mercado de trabalho. Na faixa etária mais jovem, de 25 a 34 anos, $82 \%$ das mulheres com o ensino superior estavam empregadas, percentual bem superior aos $63 \%$ das mulheres com o ensino médio e $45 \%$, com até o ensino fundamental completo. Já para os homens, na mesma faixa etária, as taxas de emprego observadas foram de $89 \%$, $84 \%$ e $76 \%$, respectivamente (BRASIL, 2019, p. 9-10).

De acordo com Barreto (2014) é preciso levar em consideração que as mulheres estudantes são, em sua maioria trabalhadoras, em dupla e muitas vezes tripla jornada, seguindo a tradição persistente no Brasil, onde elas ainda são as maiores responsáveis pelo trabalho doméstico.

Outra avaliação da autora é de que a sociedade ainda não reconhece a mulher em seu papel profissional e, assim perpetua-se as disparidades de gênero com relação a divisão sexual do trabalho, por exemplo, com as mulheres ocupando postos inferiores à sua qualificação e com remuneração menor que dos homens nos mesmos postos de trabalho.

Historicamente, o trabalho feminino fora do âmbito doméstico nunca foi culturalmente aceito, contudo, atividades como a docência, o cuidado aos doentes, às crianças e aos idosos, eram vistas com naturalidade. Pois, segundo a cultura machista, "as mulheres tem, por natureza, uma inclinaçáo pra o trato com as crianças, que elas são as primeiras e naturais educadoras" (LOURO, 1997, p. 78). Nesse sentido, atividades voltadas para a saúde e à educação, que sempre foram destinadas às mulheres no âmbito privado, poderiam, tranquilamente, ser também, no âmbito público, sem prejuízo à dominação masculina.

Nesse sentido, de acordo com Aragão e Kreutz (2010, p. 110) "lecionar traduziu-se na saída para as mulheres que desejavam se dedicar a outras atividades, sem precisar abandonar o lar e os filhos, já que era possível trabalhar somente meio período, recebendo um salário razoável e ainda ter tempo para cuidar da vida pessoal", trata-se do trabalho visto como sacerdócio, visão que se perpetua ainda nos dias atuais. 
Portanto nota-se que, mesmo com a crescente inserção das mulheres no ensino superior brasileiro, "a "ideologia da vocação" (QUEIROZ, 2000), "que se perpetua por meio de instituições e práticas sociais, faz-se introjetada e interiorizada nos sujeitos femininos e masculinos" (ÁVILA; PORTES, 2009, p. 92).

$\mathrm{O}$ modo como as mulheres participam em diversos âmbitos da vida em sociedade ainda não significa equivalência de poder e de acesso aos bens comuns. A despeito da formalização da igualdade, a ordem social continua marcada pela desigualdade, configurando uma divisão sexual de tarefas em que, para determinadas posições, carreiras e funçôes, são valorizadas características atribuídas aos homens e à masculinidade e, para outras, características atribuídas às mulheres e ao feminino. Para uma boa atuação no mercado de trabalho, por exemplo, é ainda comum que se valorizem a racionalidade, a competitividade, a busca pelo sucesso, entendidas pelo senso comum como pertinentes ao universo masculino. Já os cuidados da casa e da família, como a valorizaçâo do amor, da compaixão, da submissão, da empatia, ainda são vistos muitas vezes como características essencialmente femininas. Os diversos estereótipos atribuídos aos gêneros moldam, definitivamente, o significado atribuído às ocupações e às carreiras, pois é comum o entendimento de que há carreiras mais afeitas às mulheres e carreiras propriamente masculinas. Como consequência, o gênero também influencia no valor social atribuído às ocupaçóes no mercado de trabalho e atua do mesmo modo na universidade, onde as mulheres, ainda que presentes em número crescente, não se distribuem de modo uniforme pelas diferentes "vocaçôes" (p. 09-10).

Os dados do IBGE (2013) comprovam estas dificuldades femininas e demonstram que a maioria das brasileiras tem dupla jornada de trabalho sendo $88 \%$ delas. Já no universo masculino este percentual cai para $46 \%$. Os números indicam ainda que as mulheres trabalham o dobro dos homens exercendo as tarefas domésticas, com elas dedicando 20,6 horas/ semana contra apenas 9,8 horas/semana para os homens. Se somadas as horas de trabalho profissional e jornadas domésticas, as mulheres então trabalham aproximadamente 60/horas semanais contra 51,6 horas dos homens.

Como dito anteriormente, apesar do irrefutável avanço com as mulheres ocupando seus espaços nas academias torna-se imprescindível discutir como mudar a realidade dos números para concreçáo da cidadania buscando equidade de gênero, principalmente no que diz respeito ao reconhecimento das competências da mulher e consequente valorização no mercado de trabalho.

De acordo com Barreto (2014) avaliando números da educação superior no Brasil fica latente a presença da mulher na academia. No entanto os resultados devem chamar a atenção também para propor novas investigaçóes do lugar da mulher na sociedade, com análise de "variáveis relativas à família, reprodução, inserção no mercado de trabalho, renda, região, entre diversas outras que atingem de forma diferente homens e mulheres na vida social" (p. 42). Entretanto, a autora chama a atenção para a necessidade de que se uma reflexão imediata sobre as questóes de gênero relativas ao poder e como a mulher se insere com ocupação de postos de comando e influência política, por exemplo, e que poderiam contribuir para uma revisão mais ampla dos papéis de gênero na sociedade. 
Após a análise dos dados, esta se torna a discussão necessária, pois somente com a representação feminina quebrando paradigmas e estereótipos de gênero e reconstruindo o papel da mulher profissional é que teremos reconhecimento e redistribuição de valores, incluindo aqui os profissionais. Uma das formas de operar mudanças neste cenário seria com o aumento de recursos em pesquisas científicas e em bolsas de iniciação científica, por exemplo, incentivando as mulheres a contribuírem com a ciência.

Este estudo não tem a pretensão de esgotar o tema, pois discutir a equidade de gênero entre mulheres e homens deve ser pauta contínua na agenda de políticas públicas e sociais dos governos federal, estaduais e municipais, e ainda, das entidades não governamentais, organizaçóes sociais, organismos internacionais, como Organização das Naçóes Unidas (por meio da ONU Mulheres) Unesco e OIT. De acordo com Barreto (2014), é importante destacar ainda que a promoção da igualdade de gênero é um dos objetivos do milênio estabelecidos pela ONU, figurando em terceiro lugar entre suas oito metas.

\section{Consideraçóes finais}

A educação propicia ao indivíduo investigar, conhecer e compreender o mundo com um olhar de cidadania, dos direitos e deveres do cidadáo e, isso é de fundamental importância para que o ser humano exerça seus papéis civis, sociais e políticos em sociedade. Neste contexto, a possibilidade de se formar profissionalmente em um curso superior traz novas formas de ver o mundo e assim, abrir os horizontes dos pensamentos, ideias e atitudes das pessoas.

Para a mulher, esta formação abrange novas perspectivas de trabalho, novas oportunidades, novas experiências e consolidação do papel de cidadá transformadora da sociedade em que está inserida.

Nesse contexto, a educação torna-se o mais importante instrumento do Estado à serviço da sociedade para a promoção da cidadania plena. Embora não seja o único meio de transformação social, apresenta-se como elemento para o desenvolvimento da criticidade e de autonomia dos indivíduos.

É preciso destacar que, longe de ser considerado heroísmo, a presença das mulheres nos bancos das universidades, apresenta-se como mais um capítulo da luta feminina para ocupar espaços na sociedade, tanto no que diz respeito a questóes de direito, como para garantir a adequada divisão do trabalho doméstico e ainda a paridade salarial no mercado de trabalho.

Construir condiçôes para que a mulher ocupe vagas nas áreas de exatas e tecnológicas também deve ser foco de políticas públicas, com incentivo e fomento específico para o público feminino em pesquisas científicas, por exemplo.

É preciso entender os dados deste estudo com foco no conceito de cidadania que compreende o exercício de direitos e deveres fundamentais, com a efetiva participação de todos na 
construção de um País mais justo e igual, em níveis sociais, educacionais, culturais, econômicos e rico em diversidade.

\section{Referências}

ADORNO, Theodor W. Educação e emancipação. Tradução: Wolfgang Leo Maar. Rio de Janeiro, Paz e Terra, 1995.

ARAGÃO, Milena; KREUTZ, Lúcio. Do ambiente doméstico às salas de aula: novos espaços,velhas representaçôes. Conjectura, Caxias do Sul, v. 15, n. 3, set./dez. 2010.

ÁVILA, Rebeca Contrera; PORTES, Écio Antônio. Notas sobre a mulher contemporânea no ensino superior. Mal-Estar e Sociedade - Ano II - n. 2 - Barbacena - jun. 2009 - p. 91-106.

BARRETO, Andreia. A mulher no ensino superior: distribuição e representatividade.

Cadernos do GEA. - n.6 (jul./dez. 2014). - Rio de Janeiro: FLACSO, GEA; UERJ, LPP, 2012.

BARROS, Aidil de Jesus Paes de; LEHFELD, Neide Aparecida de Souza. Projeto de pesquisa: propostas metodológicas. 13 ed. Petrópolis, RJ: Vozes, 2002.

BOURDIEU, Pierre. A economia das trocas simbólicas. 5. ed. São Paulo, SP: Perspectiva, 2003.

BRASIL. Comitê Nacional de Educação em Direitos Humanos. Plano Nacional de Educaçáo em Direitos Humanos. Brasília: Secretaria Especial dos Direitos Humanos, Ministério da Educação, Ministério da Justiça, Unesco, 2007.

BRASIL. Constituição da República Federativa do Brasil de 1988. Disponível em: < http:// www.planalto.gov.br/ccivil_03/constituicao/constituicaocompilado.htm>. Acesso em: 17 agosto 2019.

BRASIL. Inep - Censo da Educação Superior. Instituto Nacional de Estudos e Pesquisas Educacionais Anísio Teixeira (Inep/MEC). Dados do Censo da Educaçáo Superior.

Disponível em: < http://portal.inep.gov.br/artigo/-/asset_publisher/B4AQV9zFY7Bv/content/ dados-do-censo-da-educacao-superior-as-universidades-brasileiras-representam-8-da-rede-masconcentram-53-das-matriculas/21206>. Acesso em: 17.set.2019.

BRASIL. Inep - Censo da Educação Superior. Instituto Nacional de Estudos e Pesquisas Educacionais Anísio Teixeira (Inep/MEC). Mulheres são maioria na educaçáo profissional e nos cursos de graduação. Disponível em: < http://portal.inep.gov.br/artigo/-/asset_publisher/ $\mathrm{B} 4 \mathrm{AQV} 9 \mathrm{zFY7Bv/content/mulheres-sao-maioria-na-educacao-profissional-e-nos-cursos-de-}$ graduacao/21206>. Acesso em: 17.set.2019.

BRASIL. Inep - Instituto Nacional de Estudos e Pesquisas Educacionais Anísio Teixeira (Inep/ MEC). Panorama da educaçáo/Destaques do Education at a Glance 2019. Disponível em: 
<http://download.inep.gov.br/acoes_internacionais/eag/documentos/2019/Panorama_da_ Educacao_2019.pdf>. Acesso em: 17 setembro 2019.

BRASIL. Ministério da Educação. Ética e cidadania: construindo valores na escola e na sociedade. Brasília: Ministério da Educação, Secretaria de Educação Básica, 2007.

DUBET, François. As desigualdades multiplicadas. Revista Brasileira de Educaçáo, Rio de Janeiro, n. 17, p. 5-19,maio/ago. 2001.

FREIRE, P. Educação e mudança. 20. edição. Rio de Janeiro: Paz e Terra, 1994.

GUEDES, MOEMA DE CASTRO. A presença feminina nos cursos universitários e nas pós-graduaçóes: desconstruindo a ideia da universidade como espaço masculino. v.15, suplemento, p.117-132, jun. 2008.

LOURO, Guacira Lopes. Gênero, sexualidade e educação: uma perspectiva pósestruturalista. 3. ed. Petrópolis: Vozes, 1997.

MORAN, José Manuel. Como utilizar a Internet na educação. In: Ciência da Informaçáo, Brasília, v. 26, n. 2, p., May 1997. Disponível em: <http://www.scielo.br/scielo. php?script=sci_arttext\&pid=S0100-19651997000200006\&lng=en\&nrm=iso $>$. Acesso em: 20.ago.2019.

PEREIRA, Fernanda Morato da Silva, LEHFELD, Lucas de Souza. A concreção da cidadania e a mulher nas relaçôes de poder. Revista Humus. vol. 8, num. 24, 2018 disponível em: <http://www.periodicoseletronicos.ufma.br/index.php/revistahumus/article/view/9999>. Acesso em 26.ago. 2019.

PT, Partido dos Trabalhadores. Confira as universidades e institutos federais criados pelo PT - disponível em: <https://pt.org.br/confira-as-universidades-e-institutos-federais-criadospelo-pt/>. Acesso em 26. set. 2019.

QUEIROZ, D. M. Mulheres no ensino superior no Brasil. In: 23a Reunião anual da associação nacional de pesquisa e pós-graduação em educação - ANPED, 2000, Caxambu. Caderno de resumos. Rio de Janeiro: ANPED, 2000. Disponível em: <www.anped.org.br/reunioes/23/ textos/0301t.PDF>. Acesso em: abr. 2008. 